\title{
Looking for a polyp, we found a...crab!
}

\author{
Attilio Di Spiezio Sardo • Marialuigia Spinelli • \\ Carmela Coppola $\cdot$ Brunella Zizolfi $\cdot$ Carmine Nappi
}

Received: 6 April 2010 /Accepted: 19 April 2010 /Published online: 29 April 2010

(C) Springer-Verlag 2010

Keywords Hysteroscopy · Chronic endometritis .

Endometrial polyp

Chronic endometritis (CE) is an infectious or reactive process with multiple etiologies. The lesion is reportedly often associated with pelvic inflammatory disease, intermenstrual bleeding, and pelvic pain [1].

Recently, Cicinelli and coworkers [2,3] identified the hysteroscopic appearance of $\mathrm{CE}$ as characterized by the presence of endometrial micropolyps (less than $1 \mathrm{~mm}$ of size) associated with stromal edema, endometrial thickening and peri-glandular hyperhemia. These subtle lesions may be sporadic or may cover most of the endometrial surface. The detection of plasma cells in the stromal tissue of micropolyps is considered a marker of CE [4].

The association between endometrial polyps and $\mathrm{CE}$ is still unclear. However, it is likely that in both cases, impaired endometrial proliferative processes are involved.

We report on a 33-year-old woman referred to our department for primary infertility, pelvic pain, and intermenstrual spotting. Transvaginal ultrasonography showed a focal thickened endometrium suggestive for endometrial polyp. Office hysteroscopy was performed during proliferative phase using a 4-mm hysteroscope (office operative

A. Di Spiezio Sardo $(\bowtie) \cdot$ M. Spinelli $\cdot$ C. Coppola $\cdot$ B. Zizolfi C. Nappi

Department of Gynecology and Obstetrics and Pathophysiology of Human Reproduction, University of Naples "Federico II",

Via Pansini 5,

Naples, Italy

e-mail: cdispie@tin.it continuous flow hysteroscope size 4; Karl Storz GmbH \& Co., Tuttlingen, Germany) with a $30^{\circ}$-grade optic and an incorporated $5 \mathrm{Fr}$ working channel. Vaginoscopic approach and normal saline solution were used to identify external uterine ostium to distend uterine cavity. Intrauterine pressure was maintained at a constant $50-70 \mathrm{mmHg}$ with an electronic pump for irrigation and aspiration (Endomat; Karl Storz GmbH \& Co.). Neither analgesia nor anesthesia was administered to our patient. At the entrance within the uterine cavity, a "bizarre" hysteroscopic finding similar to a waterscape was detected. A brownish, $1.5 \mathrm{~cm}$-sized polypoid lesion with two foothills was detected in the fundal area (Fig. 1a) giving the appearance of a small crab (Fig. 1b); the overall endometrial surface was nonhomogeneously thickened and hyperhemic covered by multiple thin and elongated micropolyps $(1-3 \mathrm{~mm}$ size; Fig. 1a) similar to seaweeds (Fig. 1b).

Multiple endometrial biopsies were performed with grasping forceps with teeth and histology confirmed the hysteroscopically suspected diagnosis of CE

Antibiotic therapy (doxiciclin $100 \mathrm{mg}$ twice a day) was administered to our patient for 15 days. An office hysteroscopy was performed 2 months later showing a normal pinkish endometrial mucosa with the polyp crab-like being completely removed by means of 5Fr bipolar electrode (Versapoint Twizzle electrode, Gynaecare, Ethicon) and grasping forceps.

The hysteroscospic findings are often out of the ordinary and difficult to be interpreted; images taken from every-day life can help the operator to better describe such uncommon findings. Endometrial biopsy is recommended mostly to rule out infective or neoplastic endometrial conditions. 
Fig. 1 A brownish, $1.5 \mathrm{~cm}-$ sized polypoid lesion with two foothills was detected in the fundal area (a) giving the appearance of a small crab (b); the overall endometrial surface was non-homogeneously thickened and hyperhemic covered by multiple thin and elongated micropolyps (a) similar to seaweeds (b)
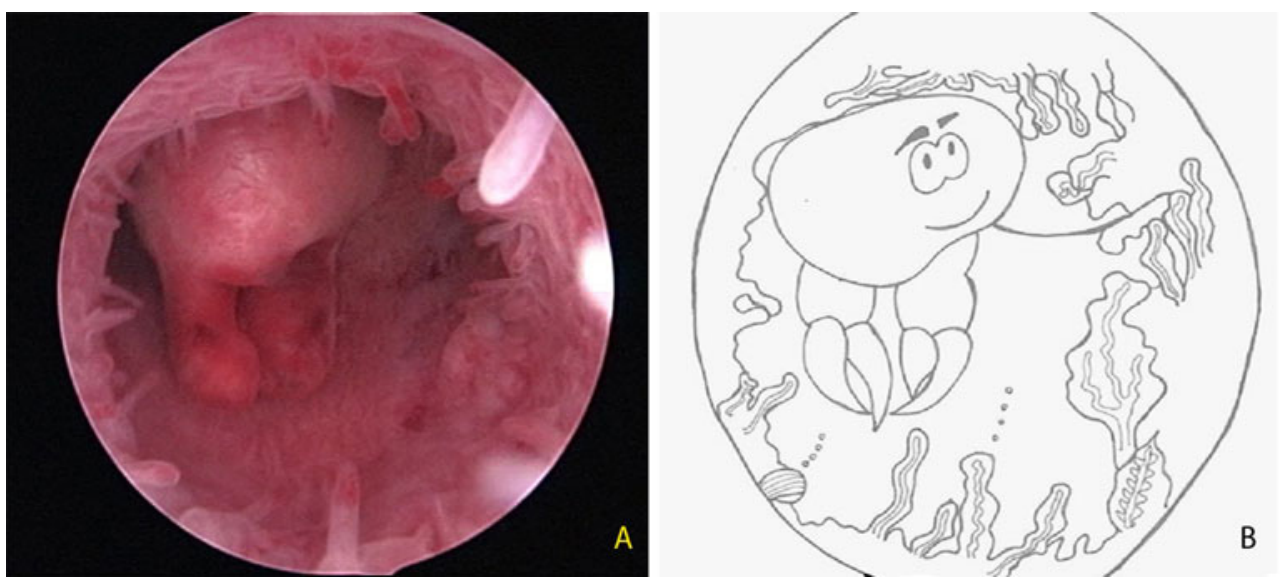

Acknowledgments The authors thank Dr Anna De Lucia for her kind collaboration to the study as a graphic designer.

Declaration of interest The authors report no conflicts of interest. The authors alone are responsible for the content and writing of the paper.

\section{References}

1. Smith M, Hagerty KA, Skipper B, Bocklage T (2010) Chronic endometritis: a combined histopathologic and clinical review of cases from 2002 to 2007. Int J Gynecol Pathol 29(1):44-50
2. Cicinelli E, Resta L, Nicoletti R, Tartagni M, Marinaccio M, Bulletti C, Colafiglio G (2005) Detection of chronic endometritis at fluid hysteroscopy. J Minim Invasive Gynecol 12(6):514518

3. Cicinelli E, Resta L, Nicoletti R, Zappimbulso V, Tartagli M, Saliani N (2005) Endometrial micropolyps at fluid hysteroscopy suggest the existence of chronic endometritis. Hum Reprod 20 (5):1386-1389

4. Yudin MH, Hillier SL, Wiesenfeld HC, Krohn MA, Amortegui AA, Sweet RL (2003) Vaginal polymorphonuclear leukocytes and bacterial vaginosis as markers for histologic endometritis among women without symptoms of pelvic inflammatory disease. Am J Obstet Gynecol 188:318-323 